Bull. Chem. Soc. Ethiop. 2013, 27(2), 205-212.

Printed in Ethiopia

ISSN 1011-3924

DOI: http://dx.doi.org/10.4314/bcse.v27i2.5

(c) 2013 Chemical Society of Ethiopia

\title{
SPECIATION OF HEAVY METALS IN STREET DUST SAMPLES FROM SAKARYA I. ORGANIZED INDUSTRIAL DISTRICT USING THE BCR SEQUENTIAL EXTRACTION PROCEDURE BY ICP-OES
}

\author{
Nilufer Ozcan and Huseyin Altundag* \\ Sakarya University, Faculty of Arts and Sciences, Department of Chemistry, 54187, Sakarya, \\ Turkey
}

(Received November 3, 2011; revised March 22, 2013)

\begin{abstract}
This paper focuses on the concentrations of heavy metals $(\mathrm{Cd}, \mathrm{Co}, \mathrm{Cr}, \mathrm{Cu}, \mathrm{Mn}, \mathrm{Ni}, \mathrm{Pb}$ and $\mathrm{Zn})$ in 20 dust samples collected from the streets of the Organized Industrial District in Sakarya, Turkey using sequential extraction procedure were determined by ICP-OES. The three-step BCR sequential extraction procedure was used in order to evaluate mobility, availability and persistence of heavy elements in street dust samples. Three operationally defined fractions isolated using the BCR procedure was: acid extractable, reducible, and oxidizable. The mobility sequence based on the sum of the BCR sequential extraction stages: Cd $(82.3 \%)>\mathrm{Mn}(80.0 \%)>\mathrm{Zn}$ $(78.8 \%)>\mathrm{Cu}(70.2 \%)>\mathrm{Ni}(65.9 \%)>\mathrm{Pb}(63.8 \%)>\mathrm{Cr}(47.3 \%)>\mathrm{Co}(32.6 \%)$. Validation of the analytical results was checked by analysis of the BCR-701 certified reference material. The concentrations of metals in the street dust samples have been shown a decrease after the each extraction stage.
\end{abstract}

KEY WORDS: Heavy metals, ICP-OES, Organized industrial district, Sequential extraction, Dust, Turkey

\section{INTRODUCTION}

The presence of heavy metals pollution is of great concern since their harmful effects on human health and the environment [1-4]. The high levels of heavy metals in sediments, soils and through transfer processes, also in groundwater and plants, may have a negative effect on animals and human health [5]. Heavy metal pollution is a serious and widespread environmental problem due to the persistent and non-biodegradable properties [6-11].

Up to now, a lot of sequential extraction procedures, mainly based on the Tessier procedures [12] have been applied to soils and sediments to fractionate metals by using different extractants or reagents to obtain more useful information about the bioavailability and mobility of metals [13].

These elements are usually associated with the principal components of the samples (carbonates, organic matter, Fe-Mn oxides and minerals) and they are available to living organisms when they dissolved in environmental materials. The information about the physicochemical properties of the elements is required for understanding their environmental behaviour, including mobility and bioavailability, the determination of total metal content in these samples after digestion with aqua regia does not provide sufficient criteria for estimating their ecological and biological effects [14-18].

The sampling area was mainly influenced from three sources natural phenomenon, namely industrial, traffic and natural sources. The mobilization of metals, in particular toxic heavy metals, has caused the increase of their concentrations in the environment [19-21]. The investigation of metal contents of the dust samples of car parking areas are vital for heavy metal pollution originated from traffic, particularly lead and recently the elements of platinum group, used in catalytic convertors for the purpose of reducing the pollutants coming from automobile emissions [22].

\footnotetext{
*Corresponding author. E-mail: altundag@sakarya.edu.tr
} 
The Standards, Measurements and Testing Programme (formerly BCR) of the European Commission proposed a three-step sequential extraction procedure that was used to determine the fractionation of trace metals, as operationally defined exchangeable and acid soluble, bound to Fe-Mn oxides, bound to organic matter and sulfites, and residual fractions [23]. Sequential extraction is a well-established method for the fractionation of heavy metal content in soils, sediments, dust and related materials [24]. The BCR sequential extraction procedure (The European Community Bureau of Reference) provides suitable information about the bioavailability and speciation of potentially toxic elements and speciation instead of total concentration of metals [25]. The most common technique used nowadays for the determination of heavy metals in environmental and biological samples involve highly sensitive spectroscopic techniques [26], such as flame atomic absorption spectroscopy (FAAS) [27, 28], inductively coupled plasma-optical emission (ICP-OES) [29] and mass spectrometry (ICP-MS) [30, 31].

In this study, a sequential extraction procedure was recommended by the Standards, Measurements and Testing Programme of the European Union, for the determination of 8 heavy metals $(\mathrm{Cd}, \mathrm{Co}, \mathrm{Cr}, \mathrm{Cu}, \mathrm{Mn}, \mathrm{Ni}, \mathrm{Pb}$ and $\mathrm{Zn}$ ) in street dust samples collected from Sakarya $\mathrm{I}$. Organized Industrial District in Sakarya, Turkey. Metal determination in the extracts were carried out by ICP-OES.

\section{EXPERIMENTAL}

Study area

The street dust samples were collected from Sakarya I. Organized Industrial District in July 2010. Sakarya I. Organized Industrial District is situated in Hanlı, Sakarya, Turkey. It was established in 1993 and its area 162 hectare. This region is a developing area and it include 63 work places which contain electric-electronic, chemicals, machinery, clothes, metal, automotive, food, and packing materials [32].

\section{Sample collection and preparation}

The street dust samples $(\mathrm{N}=20)$ were collected with a small brush from the Sakarya $\mathrm{I}$. Organized Industrial District in July 2010. The collected samples stored in air and moisture proof plastic bags and were taken to the laboratory. In the laboratory, all the samples were airdried and oven-dried at $105^{\circ} \mathrm{C}$ for $24 \mathrm{~h}$. Dried dust samples were passed through a sieve having a 230 mesh size $(63 \mu \mathrm{m})$.

\section{Reagents and solutions}

All the reagents used to prepare the extracting solutions were products of analytical-grade quality (Merck, Germany). All laboratory glassware and plastic ware were rinsed five times with distilled deionized Ultra High Quality (UHQ, chemical resistivity: $18.2 \mathrm{M} \Omega . \mathrm{cm}$ ) water (Millipore, France) after being soaked in a $\mathrm{HNO}_{3}(10 \% \mathrm{v} / \mathrm{v})$ bath overnight. Aliquots of an ICP multi element standard solution $\left(10 \mu \mathrm{g} \mathrm{mL}^{-1}\right)$ containing the analyzed elements $(\mathrm{Cd}, \mathrm{Cu}, \mathrm{Co}, \mathrm{Cr}$, $\mathrm{Mn}, \mathrm{Ni}, \mathrm{Pb}$ and $\mathrm{Zn}$ ) were used in the preparation of calibration solutions. These solutions were prepared by serial dilution with $\mathrm{HNO}_{3}(0.2 \% \mathrm{v} / \mathrm{v})$ to the required concentrations with UHQ water prior to use. The ranges of the calibration curves ( 6 points) were selected to match the expected concentrations $\left(10-320 \mu \mathrm{g} \mathrm{L}^{-1}\right)$ for all the elements of the sample studied by inductively coupled plasma-optical emission (ICP-OES). 


\section{Apparatus}

A Spectro Arcos ICP-OES (SPECTRO Kleve, Germany), Nuve KS 501 D model shaker, Nuve NF 400 (max. speed 4100 RPM) centrifuge and Schott, CG840 pH meter were used throughout the experiments. The ICP-OES operating conditions and calibration curve parameters are listed in Table 1 and Table 2, respectively.

Table 1. The operating parameters of ICP-OES.

\begin{tabular}{|l|l|}
\hline Instrument & SPECTRO ARCOS \\
\hline Viewing height $(\mathrm{mm})$ & 12 \\
\hline Wavelength & $\mathrm{nm}$ \\
\hline Replicates & 3 \\
\hline RF power $(\mathrm{W})$ & 1450 \\
\hline Nebulizer & Modified Lichte \\
\hline Plasma Torc & Quartz \\
\hline Replicate read time & 50 s per replicate \\
\hline Plasma gas flow $\left(\mathrm{Lmin}^{-1}\right)$ & 13 \\
\hline Auxiliary gas flow $\left(\mathrm{Lmin}^{-1}\right)$ & 0.7 \\
\hline Sample aspiration rate $\left(\mathrm{mLmin}^{-1}\right)$ & 2.0 \\
\hline Sample pump rate $(\mathrm{rpm})$ & 25 \\
\hline
\end{tabular}

Table 2. Calibration data of elements analyzed by ICP-OES.

\begin{tabular}{|c|c|c|c|}
\hline Elements & Wavelength $(\mathrm{nm})$ & RSD $(\%)$ & Slopes of the calibration curves \\
\hline $\mathrm{Cd}$ & 226.502 & 2.7 & 0.99976 \\
\hline $\mathrm{Co}$ & 230.786 & 3.1 & 0.99988 \\
\hline $\mathrm{Cr}$ & 267.716 & 3.8 & 0.99996 \\
\hline $\mathrm{Cu}$ & 324.754 & 1.9 & 0.99991 \\
\hline $\mathrm{Mn}$ & 257.611 & 2.4 & 0.99994 \\
\hline $\mathrm{Ni}$ & 231.604 & 4.0 & 0.99921 \\
\hline $\mathrm{Pb}$ & 220.353 & 3.3 & 0.99933 \\
\hline $\mathrm{Zn}$ & 213.856 & 2.8 & 0.99895 \\
\hline
\end{tabular}

The accuracy of the analytical procedure was checked by duplication and replication $(\mathrm{N}=3)$ of the samples. Analytical validation was conducted through the analysis of certified reference samples (BCR 701) [33].

\section{The BCR three stage sequential extraction procedure}

A three-step BCR sequential extraction procedure applied to street dust samples is summarized below.

Step 1: Exchangeable metals. $1.0 \mathrm{~g}$ dry dust samples were placed into $50 \mathrm{~mL}$ polypropylene centrifuge tubes. $40 \mathrm{~mL}$ of $0.11 \mathrm{M}$ of acetic acid was added to the tube which was then shaken for $16 \mathrm{~h}$ at of $22 \pm 5^{\circ} \mathrm{C}$ and a speed of $200 \mathrm{rpm}$. The extract was separated from the solid phase by centrifugation at $4000 \mathrm{rpm}$ for $15 \mathrm{~min}$. The supernatant liquid was decanted into a $50 \mathrm{~mL}$ polypropylene centrifuge tube and stored in a refrigerator at $4{ }^{\circ} \mathrm{C}$ prior to analysis. The residue was washed with $20 \mathrm{~mL}$ of deionized water and shaken again for 15 min and then centrifuged 
for $15 \mathrm{~min}$ at $4000 \mathrm{rpm}$. The supernatant was decanted and removed carefully to avoid loss of the solid residue [34].

Step 2: Metals bound to iron and manganese oxides. $40 \mathrm{~mL}$ of $0.1 \mathrm{M}$ hydroxylamine hydrochloride (adjusted to $\mathrm{pH} 2$ with $2 \mathrm{M} \mathrm{HNO}_{3}$ ) was added to the residue from the first step. After shaking the mixture for $16 \mathrm{~h}$ at $22 \pm 3{ }^{\circ} \mathrm{C}$ at a speed of $200 \mathrm{rpm}$, it was centrifuged for 15 min. and then decanted into a beaker. Using $20 \mathrm{~mL}$ of distilled water, the residue was washed, centrifuged and supernatant discarded.

Step 3: Metals bound to organic matter and sulfites. $10 \mathrm{~mL}$ of $8.8 \mathrm{M} \mathrm{H}_{2} \mathrm{O}_{2}(\mathrm{pH}$ of 2-3) was added carefully, in small aliquots, into the residue from step 3 in the centrifuge tube. The tube was covered loosely and digested at room temperature for $1 \mathrm{~h}$ with occasional shaking. The tube was then continuously digested for $1 \mathrm{~h}$ at $85 \pm 2{ }^{\circ} \mathrm{C}$ in a water bath with occasional shaking for the first $30 \mathrm{~min}$ and the volume was then reduced to around $2-3 \mathrm{~mL}$ by further heating of the uncovered tube. Again, the covered tube was heated to $85 \pm 2{ }^{\circ} \mathrm{C}$ and digested for $1 \mathrm{~h}$ before the volume in the uncovered tube was reduced almost to dryness after cooling, $25 \mathrm{~mL}$ of $1 \mathrm{M}$ ammonium acetate (adjusted to $\mathrm{pH} 2$ by adding of concentrated $\mathrm{HNO}_{3}$ ) was added to the residue and the tube was shaken for $16 \mathrm{~h}$ at room temperature. The extract was separated from the solid phase by centrifugation and separated from the solid phase by centrifugation and decantation as described above and stored at $4{ }^{\circ} \mathrm{C}$.

Step 4: Residual. The residue from step three was digested in a mixture (3:1) of concentrated $\mathrm{HNO}_{3}$ and $\mathrm{HCl}$. The samples were evaporated to dryness. Again, $10 \mathrm{~mL}$ aqua regia added and the same procedure was repeated. Solutions were filtered blue band filter paper. Filtrates was completed to $50 \mathrm{~mL}$ with nitric acid and stored at $4^{\circ} \mathrm{C}[25,35,36]^{\cdot}$ The determinations of $\mathrm{Cd}$, $\mathrm{Co}, \mathrm{Cr}, \mathrm{Cu}, \mathrm{Mn}, \mathrm{Ni}, \mathrm{Pb}$ and $\mathrm{Zn}$ in the extracts were performed by ICP-OES.

\section{RESULTS AND DISCUSSION}

Metals of major interest in bioavailability studies, as listed by the U.S. Environmental Protection Agency (EPA), are Al, As, $\mathrm{Be}, \mathrm{Cd}, \mathrm{Cr}, \mathrm{Cu}, \mathrm{Hg}, \mathrm{Ni}, \mathrm{Pb}, \mathrm{Se}$, and $\mathrm{Sb}$ [37]. Other metals that are presently of lesser interest to the EPA are $\mathrm{Ag}, \mathrm{Ba}, \mathrm{Co}, \mathrm{Mn}, \mathrm{Mo}, \mathrm{Na}, \mathrm{Tl}, \mathrm{V}$, and $\mathrm{Zn}$. These metals were selected because of their potential for human exposure and increased health risk.

In this study, the results of heavy metal partitioning in street dust samples were analyzed with three-stage sequential extraction procedures. The extractable contents of $\mathrm{Cd}, \mathrm{Cr}, \mathrm{Cu}, \mathrm{Ni}$, $\mathrm{Pb}, \mathrm{Zn}, \mathrm{Mn}$, Co and the extracted percentages of these metals with respect to the sums of 4 fractions in the street dusts from each extraction step are shown in Table 3 and Figure 1. The highest mean concentrations (based on the sum of the first three fractions) were found for $\mathrm{Cd}$, $\mathrm{Mn}$ and $\mathrm{Zn}$.

Sequential extraction procedures. Fraction 1: exchangeable, water and acid soluble; Fraction 2: reducible iron and manganese oxyhydroxide; Fraction 3: oxidisable organic matter and sulfites; Fraction 4: residual, to be made up to four stages.

The mobility sequence based on the sum of the BCR sequential extraction stages: Cd $(82.3 \%)>\mathrm{Mn}(80.0 \%)>\mathrm{Zn}(78.8 \%)>\mathrm{Cu}(70.2 \%)>\mathrm{Ni}(65.9 \%)>\mathrm{Pb}(63.8 \%)>\mathrm{Cr}(47.3 \%)>$ Co $(32.6 \%)$. Bioavailability and mobility of metals can be related to solubility. The concentrations (\%) of the metals in mobile phases of the samples based on the sums of the BCR sequential extraction stages (F1, F2, F3 and Residual) are in the following order: 
F1: $\mathrm{Ni}>\mathrm{Mn}>\mathrm{Cd}>\mathrm{Zn}>\mathrm{Pb}>\mathrm{Cr}>\mathrm{Co}>\mathrm{Cu} ; \mathrm{F} 2: \mathrm{Mn}>\mathrm{Pb}>\mathrm{Cd}>\mathrm{Cr}>\mathrm{Zn}>\mathrm{Ni}>\mathrm{Co}>\mathrm{Cu}$ F3: $\mathrm{Cu}>\mathrm{Zn}>\mathrm{Cd}>\mathrm{Pb}>\mathrm{Cr}>\mathrm{Co}>\mathrm{Mn}>\mathrm{Ni}$; Residual: $\mathrm{Co}>\mathrm{Cr}>\mathrm{Pb}>\mathrm{Ni}>\mathrm{Cu}>\mathrm{Zn}>\mathrm{Mn}>$ $\mathrm{Cd}$

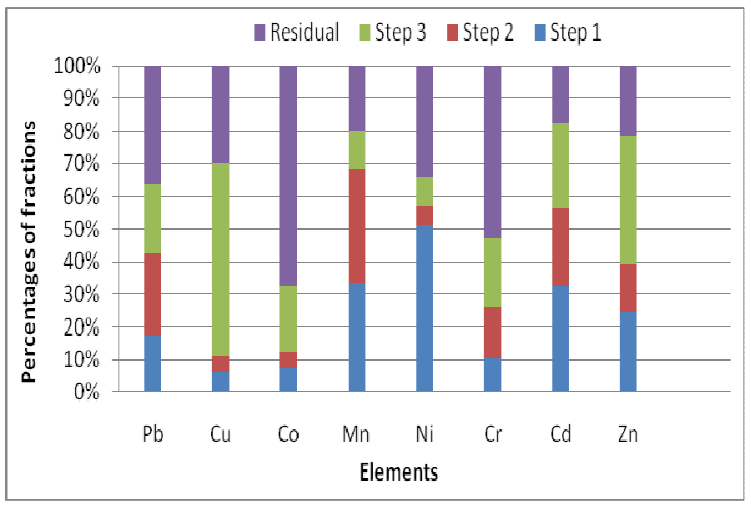

Figure 1. Percentage of $\mathrm{Pb}, \mathrm{Cu}, \mathrm{Co}, \mathrm{Mn}, \mathrm{Ni}, \mathrm{Cr}, \mathrm{Cd}$ and $\mathrm{Zn}$ extracted in each step of the sequential extraction procedure for street dust samples at Sakarya, Turkey.

Table 3. Mean concentration of metals extracted from street dust samples at each fraction of the sequential extraction (mean \pm S.D.in $\mu \mathrm{g} \mathrm{g}^{-1}$ ).

\begin{tabular}{|c|c|c|c|c|c|c|c|c|c|c|c|}
\hline \multirow{3}{*}{ 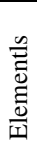 } & \multicolumn{6}{|c|}{ Fractions } & \multirow{2}{*}{\multicolumn{2}{|c|}{ Residual $^{\mathrm{a}}$}} & \multirow{3}{*}{\begin{tabular}{|c|c}
$\begin{array}{c}\sum_{\text {(F1+F2 }+\mathrm{F} 3} \\
\text { Residual) }\end{array}$ \\
Mean $\pm \mathrm{SD}$
\end{tabular}} & \multirow{3}{*}{$\begin{array}{c}\text { aqua regia } \\
\text { analysis } \\
\text { Mean } \pm \text { SD }\end{array}$} & \multirow[b]{3}{*}{$\begin{array}{c}\text { Recovery } \\
\%\end{array}$} \\
\hline & \multicolumn{2}{|l|}{$\mathrm{F} 1$} & \multicolumn{2}{|l|}{$\mathrm{F} 2$} & \multicolumn{2}{|l|}{ F3 } & & & & & \\
\hline & Mean \pm SD & $\begin{array}{c}\text { Ratio } \\
\%\end{array}$ & Mean \pm SD & $\begin{array}{c}\text { Ratio } \\
\% \\
\end{array}$ & Mean \pm SD & $\begin{array}{c}\text { Ratio } \\
\%\end{array}$ & Mean \pm SD & $\begin{array}{c}\text { Ratio } \\
\%\end{array}$ & & & \\
\hline $\mathrm{Pb}$ & $48.6 \pm 0.05$ & 17.7 & $67.9 \pm 0.8$ & 24.7 & $59.0 \pm 0.5$ & 21.5 & $99.6 \pm 1.1$ & 36.2 & $275.1 \pm 2.5$ & $272.3 \pm 1.9$ & 101 \\
\hline $\mathrm{Cu}$ & $4.3 \pm 0.04$ & 6.1 & $3.6 \pm 0.03$ & 5.2 & $41.4 \pm 0.3$ & 58.9 & $21.0 \pm 0.5$ & 29.8 & $70.3 \pm 0.9$ & 1.3 & 98 \\
\hline Co & $1.4 \pm 0.02$ & 7.2 & $1.1 \pm 0.04$ & 5.3 & $4.0 \pm 0.1$ & 20.1 & $13.5 \pm 0.3$ & 67.4 & $20.0 \pm 0.5$ & $20.3 \pm 1.2$ & 99 \\
\hline $\mathrm{Mn}$ & $85.1 \pm 0.1$ & 33.3 & $88.5 \pm 1.2$ & 34.7 & $30.8 \pm 0.2$ & 12.1 & $50.9 \pm 0.4$ & 20.0 & $255.3 \pm 1.9$ & $252.7 \pm 2.4$ & 101 \\
\hline $\mathrm{Ni}$ & $31.4 \pm 0.3$ & 51.5 & $3.4 \pm 0.2$ & 5.6 & $5.3 \pm 0.03$ & 8.75 & $20.8 \pm 0.1$ & 34.1 & $60.9 \pm 0.6$ & $59.7 \pm 1.6$ & 102 \\
\hline $\mathrm{Cr}$ & $17.7 \pm 0.4$ & 10.6 & $25.7 \pm 0.3$ & 15.4 & $35.5 \pm 0.3$ & 21.2 & \begin{tabular}{|l|}
$88.0 \pm 0.1$ \\
\end{tabular} & 52.7 & $166.9 \pm 1.1$ & $170.3 \pm 2.6$ & 98 \\
\hline $\mathrm{Cd}$ & $1.6 \pm 0.1$ & 32.7 & $1.2 \pm 0.03$ & 23.9 & $1.3 \pm 0.02$ & 25.8 & $0.9 \pm 0.06$ & 17.7 & $5.0 \pm 0.2$ & $4.8 \pm 1.2$ & 102 \\
\hline $\mathrm{Zn}$ & $65.1 \pm 0.4$ & 24.6 & $38.7 \pm 0.02$ & 14.6 & $104.8 \pm 1.3$ & 39.6 & $56.2 \pm 0.4$ & 21.2 & $264.8 \pm 2.1$ & $260 \pm 1.8$ & 102 \\
\hline
\end{tabular}

${ }^{\mathrm{a}}$ This is not a step of BCR protocol.

The total metal analysis was performed with 0.5 and $1.0 \mathrm{~g}$ of dust samples using aqua regia as digestion solution. Dried dust $(0.5 \mathrm{~g}$ and $1.0 \mathrm{~g})$ samples were transferred to digestion glass tubes and digested with $12 \mathrm{~mL}$ of aqua regia solution. Digestion was carried out at $140{ }^{\circ} \mathrm{C}$ for 2 h. Cooled digested samples were transferred to volumetric flasks and made up to $25 \mathrm{~mL}$ with ultrapure water. Metal concentrations in digested samples (three replicates) were analyzed by ICP-OES. All the strong acid mixtures were prepared just before the analysis of total metal contents of the samples.

Comparison of the pseudo-total elemental concentration and sequential extraction results recoveries $\%$ are given in Table 3 . As can be seen, no significant differences were observed between the aqua-regia digestion and the sum of extracted metals following the sequential extraction procedure. The $\mathrm{pH}$ values of dust samples collected from five locations were observed to be in the range of 7.08-8.80. The $\mathrm{pH}$ was adjusted to the desired value by adding dilute 1:5 (w/v) distilled water. 
Table 4. Determined and reference values of extractable heavy metals on BCR 701 (mean $(\mu \mathrm{g} / \mathrm{g} \pm \mathrm{RSD} \%$ ) $\mathrm{N}=3)$.

\begin{tabular}{|l|l|l|}
\hline Standard reference material (CRM) & $\begin{array}{l}\text { Analyzed } \\
\text { value }\end{array}$ & Certified value \\
\hline BCR-sequential extraction (BCR-701) & \multicolumn{2}{l|}{} \\
\hline $\mathrm{Step} \mathrm{1}$ & $7.16 \pm 0.12$ & $7.34 \pm 0.35$ \\
\hline $\mathrm{Cd}$ & $2.23 \pm 0.16$ & $2.26 \pm 0.16$ \\
\hline $\mathrm{Cr}$ & $48.1 \pm 1.1$ & $49.3 \pm 1.7$ \\
\hline $\mathrm{Cu}$ & $15.3 \pm 0.4$ & $15.4 \pm 0.9$ \\
\hline $\mathrm{Ni}$ & $2.99 \pm 1.15$ & $3.18 \pm 0.21$ \\
\hline $\mathrm{Pb}$ & $208 \pm 5$ & $205 \pm 6$ \\
\hline $\mathrm{Zn}$ & \multicolumn{2}{l|}{} \\
\hline $\mathrm{Step} 2$ & $3.74 \pm 0.09$ & $3.77 \pm 0.28$ \\
\hline $\mathrm{Cd}$ & $46.8 \pm 0.1$ & $45.7 \pm 2.0$ \\
\hline $\mathrm{Cr}$ & $125.4 \pm 2.3$ & $124 \pm 3$ \\
\hline $\mathrm{Cu}$ & $26.1 \pm 1.1$ & $26.6 \pm 1.3$ \\
\hline $\mathrm{Ni}$ & $122.0 \pm 3.1$ & $126 \pm 3$ \\
\hline $\mathrm{Pb}$ & $111 \pm 4$ & $114 \pm 5$ \\
\hline $\mathrm{Zn}$ & \multicolumn{2}{l|}{} \\
\hline $\mathrm{Step} 3$ & $0.26 \pm 0.10$ & $0.27 \pm 0.06$ \\
\hline $\mathrm{Cd}$ & $142 \pm 1$ & $143 \pm 7$ \\
\hline $\mathrm{Cr}$ & $56.5 \pm 0.2$ & $55.2 \pm 4.0$ \\
\hline $\mathrm{Cu}$ & $15.8 \pm 0.9$ & $15.3 \pm 0.9$ \\
\hline $\mathrm{Ni}$ & $8.6 \pm 2.8$ & $9.3 \pm 2.0$ \\
\hline $\mathrm{Pb}$ & $45.0 \pm 2.3$ & $45.7 \pm 4.0$ \\
\hline $\mathrm{Zn}$ & & \\
\hline
\end{tabular}

The precision and accuracy of the proposed procedure were evaluated by using a certified reference material BCR 701. The recovery rates for heavy metals in the standard reference material were obtained between $92.7 \%$ and $103.4 \%$ and can be explained by the values of the uncertainty. The results showed a good agreement between the obtained and the certified values for the metals analyzed [33]. The results are given in Table 4.

\section{Electron diffraction spectroscopy}

The scanning electron microscope (SEM) uses a focused beam of high-energy electrons to generate a variety of signals at the surface of solid specimens [38]. The signals that derive from electron-sample interactions reveal information about the sample including external morphology, chemical composition, and crystalline structure and orientation of materials making up the sample. The SEM is also capable of performing analyses of selected point locations on the sample; this approach is especially useful in qualitatively or semi-quantitatively determining chemical compositions (using electron diffraction spectroscopy) [38]. In these studies, performed by SEM, it was observed that the metals contents have decreased after the application of each sequential extraction stage and finally after the aqua regia leaching step, almost the heavy metals were not retained on the residue. The results show that both methods are in harmony. The results are given in Table 5.

Electron diffraction spectroscopy (EDS) can provide elemental analysis on selected areas. The results are little different with ICP-OES data due to non homogeneous distribution in the samples. 
Table 5. The analysis with electron diffraction spectroscopy (EDS).

\begin{tabular}{|l|c|c|c|c|c|}
\hline Element & Not extracted (\%) & F1 (\%) & F2 (\%) & F3 (\%) & Residual (\%) \\
\hline $\mathrm{Cr}$ & 0.121 & 0.166 & 0.093 & 0.099 & 0.080 \\
\hline $\mathrm{Mn}$ & 0.131 & 0.130 & 0.276 & 0.065 & 0.000 \\
\hline $\mathrm{Co}$ & 0.358 & 0.000 & 0.269 & 0.000 & 0.000 \\
\hline $\mathrm{Cu}$ & 2.186 & 1.937 & 1.999 & 1.426 & 0.513 \\
\hline $\mathrm{Zn}$ & 0.986 & & & 1.336 & \\
\hline
\end{tabular}

\section{CONCLUSION}

In this study, the results of heavy metal partitioning in street dust samples for a three stage sequential extraction procedures were given the distribution and bioavailability of the metals at each extraction stage. It may be concluded that the bioavailability of any metal is related to its chemical forms in street dust structure rather than its total concentration. The applicability of the BCR method is easy, reasonably and inexpensive. The precision and accuracy of the proposed procedure were evaluated by using a certified reference material BCR 701. In environmental studies the determination of the different ways of binding gives more information on trace metal mobility, as well as on their availability or toxicity, in comparison with the total element content. BCR sequential extraction procedure and application of appropriate analytical techniques can encourage wider use of speciation analysis in the laboratory. The method of sequential extraction can be used in the analysis of various environmental samples such as soil, dust, airborne particulate, biological materials and bottom sediments. In further work is thought not only to investigate chemical composition of street dusts by the BCR sequential method, but also to identify their pollution sources according to different particle size.

\section{ACKNOWLEDGEMENTS}

This work was supported partly by Sakarya University Scientific Research Foundation with Project Number 2011-50-01-015.

\section{REFERENCES}

1. Soylak, M.; Uzek, U.; Narin, I.; Tuzen, M.; Turkoglu, O.; Elci, L. Fresen. Environ. Bull. 2004, 13, 454.

2. Gupta, V.K.; Mittal, A.; Gajbe, V.; Mittal, J. Ind. Eng. Chem. Res. 2006, 45, 1146.

3. Kot, A.; Namiesnik, J. Trends Anal. Chem. 2000, 19, 69.

4. Gupta, V.K.; Gupta, M.; Sharma, S. Water Res. 2001, 35, 1125.

5. Rao, C.R.M.; Sahuquillo, A. Anal. Chim. Acta 2010, 662, 128.

6. Kazi, T.G.; Jamali, M.K.; Arain, M.B.; Afridi, H.I.; Jalbani, N.; Raja A. Sarfraz, R.A., Ansari, R. J. Hazard. Mater. 2009, 161, 1391.

7. Gupta, V.K.; Vinod, K.; Imran, A.; Vipin, K. J. Colloid Interf. Sci. 2007, 315, 87.

8. Mester Z.; Cremisini C.; Ghiara, E.; Morabito, R. Anal. Chim. Acta 1998, 359, 133.

9. Gupta, V.K.; Ali, I. Sep. Purif. Technol. 2000, 18, 131.

10. Gupta, V.K.; Jain, C.K.; Ali, I.; Sharma, M.; Saini, V.K. Water Res. 2003, 37, 4038.

11. Gupta, V.K.; Sharma, S. Ind. Eng. Chem. Res. 2003, 42, 6619.

12. Tessier, A. Anal.Chem. 1979, 51, 844.

13. Tokalioğlu, S.; Kartal, S.; Birol, G. J. Environ. Monitor. 2003, 5, 468.

14. Gupta, V.K.; Rastogi, A. J. Hazard. Mater. 2008, 152, 407.

Bull. Chem. Soc. Ethiop. 2013, 27(2) 
15. Sutherland, R.A.; Tack F.M.G. Anal. Chim. Acta, 2002, 454, 249.

16. Gupta, V.K.; Ali, I. J. Colloid Interf. Sci. 2004, 271, 321.

17. Srivastava, S.K.; Gupta, V.K.; Mohan, D. J. Environ. Eng-Asce. 1997, $123,461$.

18. Gupta, V.K.; Mohan, D.; Sharma, S. Sep. Sci. Technol. 1998, 33, 1331.

19. Gupta, V.K.; Rastogi, A.; Nayak, A. J. Colloid Interf. Sci. 2010, 342, 135.

20. Benitez, L.N.; Dubois, J.P. Int. J. Environ. Anal. Chem. 1999, 75, 261.

21. Gupta, V.K.; Imran, A. Environ. Sci. Technol. 2008, 42, 766.

22. Tokalıŏlu, S., Kartal, S., Birol, G. Turk. J. Chem. 2003, 27, 333.

23. Tokalığlu, Ş., Kartal, Ş. Atmos. Environ. 2006, 40, 2797.

24. Elass, K.; Laachach, A.; Azzi, M. Ann. Chim. 2004, 94, 325.

25. Nemati, K.; Abu Bakar, N.K.; Sobhanzadeh, E.; Abas, M.R. Microchem. J. 2009, 92, 165.

26. Karimi, H.; Ghaedi, M. Fresen. Environ. Bull. 2008, 17, 2027.

27. Jamali, M.K.; Kazi, T.G.; Afridi, H.I.; Arain, M.B.; Jalbani, N.; Memon, A.R. J. Environ. Sci. Health A 2007, 42, 649.

28. Dundar, M.S.; Altundag, H. Environ. Monit. Assess. 2007, 128, 177.

29. Altundag H.; Tuzen, M. Food Chem. Toxicol. 2011, 49, 2800.

30. Altundag, H.; Dundar, M.S. Fresen. Environ. Bull. 2009, 18, 2102.

31. Altundag, H.; Dundar, M.S. Fresen. Environ. Bull. 2009, 18, 98.

32. Sakarya I. Organized Industrial District, web site, http://www.sosb.org.tr/; accessed on May 21, 2011.

33. European Comission Joint Research Center, BCR 701, Institute for Reference Materials and Measurements (IRMM), Geel, Belgium; 2001.

34. Pueyo, M.; Mateu, J.; Rigol, A.; Vidal, M.; Lopez-Sanchez, J.F; Rauret, G. Environ Pollut. 2008, $152,330$.

35. Cuong D.; Obbard J. Appl. Geochem. 2006, 21, 1335.

36. Sysalova J.; Szakova J. Environ. Res. 2005, 101, 287.

37. McKinney, J.; Rogers, R. Int. J. Environ. Sci. Technol. 1992, 26, 1298.

38. Unakar, J.N.; Tsui, J.Y. Ophthalmic Res. 1981, 13, 20. 